Гречихин Владимир Григорьевич

доктор философских наук, профессор кафедры истории и теории социологии

Московского государственного

университета им. М.В. Ломоносова

\section{ПРОБЛЕМЫ СОЦИАЛЬНОЙ СПРАВЕДЛИВОСТИ И НЕРАВЕНСТВА В СОВРЕМЕННОМ РОССИЙСКОМ ОБЩЕСТВЕ}

Аннотация:

В данной статье рассмотрен такой актуальный на сегодняшний день вопрос, как проблемы социальной справедливости и неравенства в современном российском обществе. Представлен анализ мнения жителей России о том, что они считают справедливостью и в чем, по их мнению, выражается социальное неравенство. Также в статье представлены показатели уровня доходов самых богатых и самых бедных слоев населения России, показана разница между ними. Указано на негативное отношение со стороны общества к существующему в настоящее время неравенству. Делается вывод о том, что проблема социальной справедливости и неравенства становится с каждым годом все более острой, более актуальной для большей части населения нашей страны. Следовательно, со стороны государства требуется разработка и принятие таких мер, которые позволят сгладить существующее социальное неравенство, тем самым снизив социальную напряженность и недовольство в российском обществе.

\section{Ключевые слова:}

социальное государство, социальная справедливость, социальное неравенство, уровень жизни, доходы населения, коэффициент расслоения доходов, социальные блага, социальные гарантии.
Grechikhin Vladimir Grigoryevich

\author{
D.Phil., Professor, \\ Department of Theory \\ and History of Sociology, \\ Lomonosov Moscow State University
}

\section{PROBLEMS OF SOCIAL} JUSTICE AND INEQUALITY IN MODERN RUSSIAN SOCIETY
Keywords: social state, social justice, social inequality, standard of living, population incomes, income stratification ratio, social benefits, social guarantees.

Важной особенностью человеческого общества на протяжении всего его существования был и остается запрос на справедливость, и в первую очередь на справедливость социальную. Естественно, что полного социального равенства и отсутствия несправедливости никогда не было и не будет ни в одной из стран мира, поскольку это противоречит всем существующим биологическим, экономическим законам и законам социального развития. Тем не менее, большинство ведущих современных стран реализуют определенную социальную политику, направленную на снижение расслоения общества в зависимости от доходов, а также исполняют социальные программы, которые обеспечивают максимально равный доступ всех жителей государства к социальным благам. Проблема социальной справедливости, а также сокращения социального расслоения в обществе и уровня социального неравенства по своей важности стоят на одном из первых мест для огромного количества мировых держав.

В современной отечественной социологической науке проблемы социальной справедливости активно обсуждаются. Анализ материалов этих обсуждений позволяет утверждать, что под термином «социальная справедливость» чаще всего понимается соответствие подлинной ценности конкретных людей, групп или профессий их реальным условиям жизни и положению в обществе, то есть соответствие деяний воздаяниям, прав - обязанностям, заслуг - получаемым благам и т. д. [1, с. 6].

Россия традиционно является страной, в которой запрос на социальную справедливость во все времена ее развития стоял особенно остро и имел особо важное значение. Проведенные в настоящее время социологические исследования дают очень интересные данные о том, что 
именно понимают россияне под социальной справедливостью. Вопреки широко распространенному мнению о тяге россиян к уравнительному характеру во всем, реальная картина вырисовывается совершенно иная.

Социологические опросы показали, что самым значимым проявлением социальной справедливости, по мнению 36 \% жителей России, является равенство всех перед законом. Материальную составляющую, то есть примерно одинаковый для всех уровень жизни, в качестве социальной справедливости отмечают 20 \% населения. Возможности достижения максимума своих возможностей назвали $13 \%$ опрошенных. Ответственность богатых членов общества и наличие гарантий для социально незащищенных слоев как социальную справедливость выделили $11 \%$ респондентов. Всего 6 \% россиян высказали мысль о том, что социальной справедливости просто не существует [2, с. 109].

Часть 1 статьи 7 Конституции РФ гласит, что Российская Федерация является социальным государством, политика которого направлена на создание условий, обеспечивающих достойную жизнь и свободное развитие человека [3]. То есть, наше государство обязуется обеспечивать людям равный доступ к социальным благам, тем самым поддерживая в российском обществе социальную справедливость. Однако в настоящее время ситуация такова, что социальное неравенство и расслоение общества с каждым годом все больше увеличивается, вызывая тем самым у огромной части людей недовольство проводимой социальной политикой, что, в конечном итоге, приводит к возрастанию недоверия к власти.

По итогам прошедшего 2019 года Россия вошла в число стран с самым высоким уровнем социального неравенства, где 82 \% личных богатств сконцентрировано всего у 10 \% населения страны, и 45 \% национального дохода контролирует всего 1 \% населения. Причем, 30 лет назад $1 \%$ населения контролировал около 25 \% такого дохода [4]. По данному показателю Россия уступает только странам Персидского залива, некоторым государствам Южной Америки и еще ряду развивающихся стран. Что же касается развитых стран Европы и Америки, то по сравнению с ними ситуация в России явно неудовлетворительная.

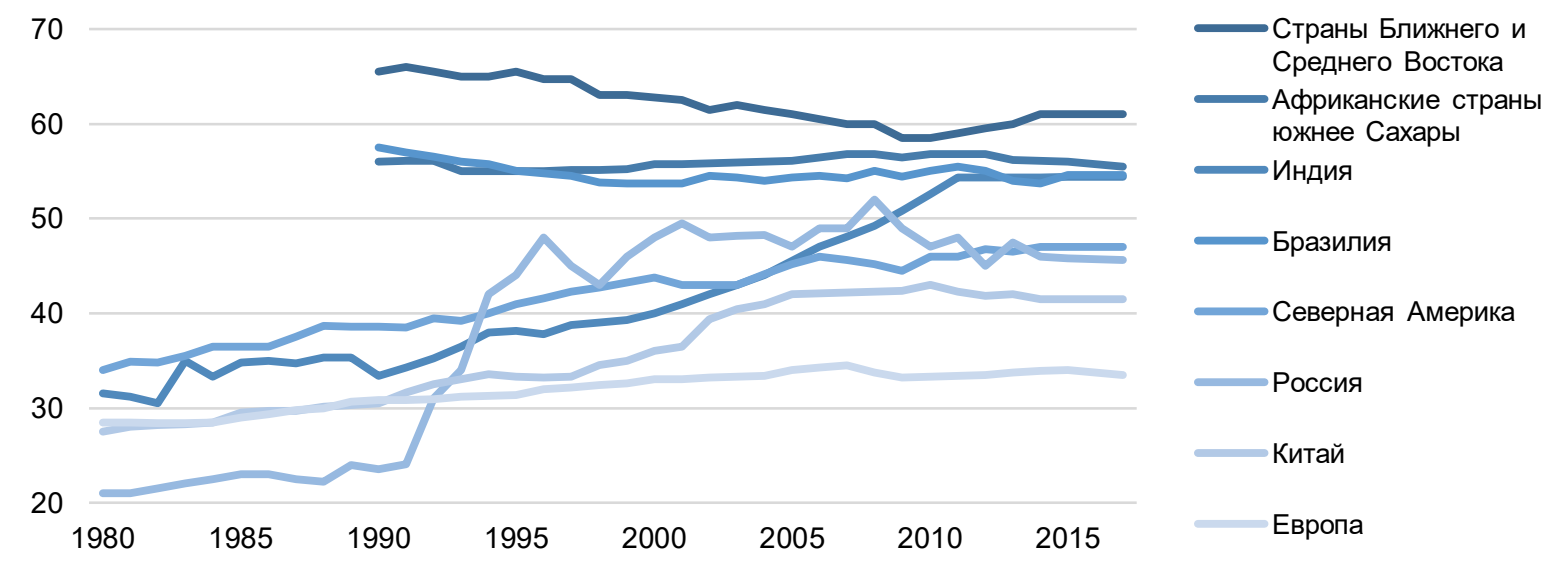

Рисунок 1 - Сравнительная характеристика уровня доходов 10 \% самых богатых граждан в общей доле национального дохода своих государств, \% [5, с. 3]

В данном случае необходимо упомянуть о статистическом показателе, который часто применяется социологами и экономистами при исследовании проблем социальной справедливости, коэффициенте расслоения доходов, называемом также индексом Джини, или индексом справедливости. Он показывает равномерность распределения дохода между членами общества. Чем выше индекс Джини, тем больше неравенство в распределении доходов между членами общества. Однако, когда он слишком низок, это свидетельствует не о наличии социальной справедливости, а только лишь о наличии искусственной уравниловки, которая совершенно не характерна для здоровой рыночной экономики. Специалисты склоняются к мнению, что наиболее благоприятная в плане социального равенства ситуация существует в тех странах, где данный показатель колеблется от 0,4 до 0,3. Что же касается России, то на сегодняшний момент индекс Джини составляет приблизительно 0,417, то есть ситуацию явно нельзя назвать благоприятной [6].

Среди российского населения, как показывают социальные опросы, именно приведенный показатель ярче всего выражает существующее социальное неравенство. Сегодня в России 84 \% жителей относят его к самому яркому проявлению неравенства в стране, более всего бо- 
лезненного для нашего общества. Однако в последние годы все большее количество людей указывают на немонетарное неравенство, самыми важными аспектами которого являются связанные с жильем и медицинской помощью.

Кроме того, в последние годы явно наметилась тенденция на повышение уровня социальной справедливости в вопросах, касающихся возможности доступа к хорошим рабочим местам, образованию и т. д. Данные, связанные с запросами на социальную справедливость в настоящее время приведены в таблице 1 [7, с. 105].

Таблица 1 - Наиболее болезненные неравенства для российского общества, \%

\begin{tabular}{|c|l|c|}
\hline \multicolumn{1}{|c|}{ Тип неравенства } & $\begin{array}{c}\text { Воспринимается } \\
\text { болезненно обществом }\end{array}$ \\
\hline 1 & Доходы & 84 \\
\hline 2 & Доступ к медицинской помощи & 70 \\
\hline 3 & Жилищные условия & 64 \\
\hline 4 & Доступ к хорошим рабочим местам & 52 \\
\hline 5 & Доступ к образованию & 48 \\
\hline 6 & Доступ к возможностям для детей из разных слоев общества & 22 \\
\hline 7 & Доступ к возможностям отдыха и проведения досуга & 20 \\
\hline 8 & Доступ к возможностям обладания собственностью & 9 \\
\hline 9 & Доступ к знакомствам с «нужными людьми» & 9 \\
\hline 10 & Доступ к возможностям добраться в нужные места & 6 \\
\hline 11 & Да общественном транспорте & 4 \\
\hline 12 & Доступ к культурным и художественным ценностям & 2 \\
\hline 13 & Доступ к физическим возможностям & \\
\hline 14 & Нет претензий к неравенству & \\
\hline
\end{tabular}

Анализ таблицы позволяет с уверенностью говорить о том, что население страны в своем подавляющем большинстве отмечает существующую социальную несправедливость по основным параметрам развития современного российского общества. Всего лишь 2 \% россиян считают, что данной проблемы на сегодняшний день в стране не существует.

Кроме того, материалы проведенного в 2019 году социологами РАНХиГС опроса четко иллюстрируют динамику и направленность роста числа граждан, недовольных проявлениями социальной несправедливости в России (таблица 2 [8, с. 5]).

\section{Таблица 2 - Динамика проявлений недовольства социальной несправедливостью} в России

\begin{tabular}{|c|c|c|}
\hline Проявление социальной несправедливости & 2009 год & 2019 год \\
\hline Неравенство в получении хорошего заработка & 53,5 & 56,5 \\
\hline В пенсионном обеспечении & 31,2 & 41,9 \\
\hline В слабой защите от безработицы & 34,2 & 37,4 \\
\hline $\begin{array}{l}\text { В неравенстве возможностей на получение медицинской } \\
\text { помощи и образования }\end{array}$ & 35,3 & 36,4 \\
\hline В неравенстве права на судебную защиту & 16,1 & 23 \\
\hline В необеспечении личной защиты и неприкосновенности & 15,4 & 17,3 \\
\hline В неравенстве политических прав & 6,5 & 17 \\
\hline Другое & 3,3 & 2,5 \\
\hline
\end{tabular}

Анализ данных, приведенных в таблице, показывает, что за последние 10 лет недовольство социальной несправедливостью явно возросло. Причем, акцент сместился в сторону недовольства неравенством политических прав, а также в сфере неравенства прав на судебную защиту. Это свидетельствует о снижении доверия к органам судебной власти среди россиян и озабоченности политическим неравенством. Также существенно вырос показатель недоверия к пенсионному обеспечению, что, бесспорно, напрямую связано с проводящейся в стране уже много лет пенсионной реформой.

Говоря о причинах социальной несправедливости, следует подчеркнуть, что большинство россиян склонны винить в этом государственную власть, которая проводит непродуманную социальную политику. К примеру, в том случае, когда речь идет об имущественном неравенстве и бедности, 36 \% россиян в качестве первопричин уверенно отмечают проводимые экономические реформы. К этому следует добавить, что 37 \% респондентов считают, что в настоящее время в России наблюдается существенное сокращение социальных гарантий и фактический отказ государства от социального обеспечения тех слоев населения, которые в нем нуждаются [9]. При 
этом не скидывается со счетов и то, что во многих случаях люди сами виноваты в том, что их доход не соответствует желаемому, что объясняется их чрезмерной пассивностью, отсутствием соответствующего образования и квалификации, ведением аморального образа жизни и т. д.

Запрос на сокращение социального неравенства и установление социальной справедливости жители России предъявляют именно государству. Например, согласно опросам, около 75 \% россиян высказывают мнение о том, что ответственность за справедливое распределение материальных благ должны нести именно федеральные власти [9]. Причем, это является, по мнению большинства, гораздо более важной и актуальной задачей, чем просто борьба с бедностью.

Также необходимо отметить, что в настоящее время большинство жителей России, даже имея склонность к большей социальной однородности, в качестве социальной справедливости называют не равенство доходов, а равенство возможностей. Особенно это характерно для молодежной аудитории, которая стремится получить хорошее образование и стать высококлассными специалистами, получающими прекрасный доход. 59 \% респондентов, отвечая на вопрос о понимании социальной справедливости в обществе, указали именно на равенство возможностей [10].

Подводя итог вышесказанному, следует отметить, что проблема социальной справедливости и неравенства в современной России существует, и игнорировать данный факт нельзя. Несмотря на возросшую толерантность общества, данная проблема приводит к социальной напряженности и возникновению недоверия к государственной власти. Исходя из анализа данных социологических исследований совершенно очевидно, что российское общество в настоящее время в качестве социальной справедливости понимает совсем не материальную уравниловку, а равенство всех перед законом, то есть на первое место выходит правовая составляющая. Это, бесспорно, свидетельствует о возрастании гражданской позиции в российском обществе.

Кроме того, существует запрос на то, чтобы положение каждого члена общества определялось его реальными трудовыми усилиями, чтобы хорошие рабочие места были доступны именно высококвалифицированным специалистам, а не случайным людям, имеющим «полезные знакомства».

Особое внимание нужно обратить на то, что решение данных проблем лежит, в первую очередь, на государстве, которое не просто способно, но и обязано проводить грамотную и взвешенную социальную политику, обеспечивающую запросы современного общества. Государство для достижения положительного эффректа в вопросах сокращения социального неравенства обязано учитывать мнение россиян, иметь с ними обратную связь. Это достигается путем проведения опросов, при личном контакте с людьми представителей государственной власти и т. д. В свою очередь граждане России должны говорить о наличии тех социальных проблем, которые их волнуют, предлагать свои пути решения таковых, принимать активное участие в различных социальных опросах, иным образом идти на контакт с государственной властью. Только при совместной деятельности государства и общества возможно достижение компромисса по острым социальным вопросам, а также эффрективное решение существующих в настоящее время социальных проблем, в том числе и проблемы социального неравенства.

\section{Ссылки:}

1. Возьмитель А.А. Социальное неравенство и его риски в советской и постсоветской России // Власть. 2016. № 8. С. 6-15.

2. Руденкин В.Н. Проблемы справедливости в современном российском обществе // Вопросы управления. 2016 . № 7. C. $103-123$.

3. Конституция Российской Федерации (принята всенародным голосованием 12.12.1993) (с последними изменениями на 2020 год) [Электронный ресурс]. Доступ из справ.-правовой системы «КонсультантПлюс».

4. Артемов К.Е. Социальное неравенство в России как угроза национальной безопасности страны [Электронный ресурс] // Экономика и бизнес. URL: https://inance.ru/2020/02/sotsialnoe-neravenstvo/ (дата обращения: 30.03.2020).

5. Соловьева О.О. Россия оказалась в мировых лидерах по неравенству // Экономика. - 2019. - № 12. - С. 3 - 5.

6. Сирвида С. Коэффициент Джини: все ли равны? [Электронный ресурс] // Экономика. URL: https://journal.open-broker.ru/economy/koefficient-dzhini/ (дата обращения: 30.03.2020).

7. Мареева С.В. Социальное неравенство и социальная структура современной России в восприятии населения // Вестник социологии. 2019. № 11. С. 102-122.

8. Сергеев М. Социальная несправедливость остается ключевой проблемой // Экономика. 2020. № 6. С. 4-6.

9. Индекс социальных настроений [Электронный ресурc] // Официальный сайт Левада-Центр. URL: https://www.levada.ru/indikatory/sotsialno-ekonomicheskie-indikatory/ (дата обращения: 30.03.2020).

10. Социальное неравенство в социологическом измерении [Электронный ресурс] // Официальный сайт института социологии. URL: https://www.isras.ru/analytical_report_Social_inequality_3.html (дата обращения: 30.03.2020). 